\title{
REFLEXIONES EN TORNO A LA REFORMA CONSTITUCIONAL Y LEGAL EN MATERIA DE COMBATE A LA CORRUPGIÓN EN MÉXICO*
}

\author{
Daniel MÁRQUEZ ${ }^{* *}$
}

SUMARIO: I. Las reformas constitucional y legal en materia de combate a la corrupción. II. El Sistema Nacional Anticorrupción. III. La Ley General de Responsabilidades Administrativas. IV. Bibliografia.

\section{LAS REFORMAS GONSTITUCIONAL Y LEGAL EN MATERIA DE COMBATE A LA GORRUPGIÓN}

En otros espacios hemos debatido en torno al problema de la corrupción, también hemos argumentado en torno al debate conceptual asociado a la voz "fzeiro", corromper; y el adjetivo "afzartos", o sea, incorruptible; también destacamos el contenido de la palabra latina "rumpere", con sus sentidos de arrancar, aplastar, arruinar, romper. Sostuvimos que las definiciones de corrupción se enfocan en temas económicos, éticos, políticos, jurídicos o sociales. También, al advertir la complejidad del tema corrupción, nos pronunciamos por una "diasdoralogía", una ciencia que aborde de manera integral el fenómeno de la corrupción. ${ }^{1}$

* Artículo recibido el 23 de febrero de 2018 y aceptado para su publicación el 15 de abril de 2018.

** ORCID: 000-0001-7557-4525, Instituto de Investigaciones Jurídicas.

1 Véase Márquez Gómez, Daniel (coord.), Corrupción y Sistema Nacional Anticorrupción: temas y problemas, México, Tribunal de lo Contencioso Administrativo del Estado de Guanajuato-Novum, 2016; Márquez Gómez, Daniel, El marco jurídico para la operación del Sistema Nacional Anticorrupción. Constitucionalidad y legalidad del combate a la corrupción mexicano, México, Tribunal de Justicia Administrativa del Estado de Guanajuato-Novum, 2017; Márquez Gómez, Daniel, El marco jurídico para la operación del Sistema Nacional Anticorrupción. Combate a la corrupción, fiscalización y transparencia, México, Tribunal de Justicia Administrativa del Estado de Guanajuato-Novum, 2017; Márquez, Daniel, "La diasdoralogía como el estudio integral del fenómeno de la corrupción, documento inédito en poder del autor", ponencia en el IX Congreso Mexicano y II Iberoamericano de Derecho Administrativo.

Boletín Mexicano de Derecho Comparado, nueva serie, año XLX, núm. 152, mayo-agosto de 2018, pp. 787-803.

Esta obra está bajo una Licencia Creative Commons Atribución-NoComercial-SinDerivar 4.0 Internacional, IIJ-UNAM. 
Sin considerar las reformas de finales del siglo XIX y principios del siglo XX, desde 1982, el régimen de combate a la corrupción mexicano no había sufrido grandes transformaciones. ${ }^{2}$

Por eso llamó la atención que, con escaso debate social sobre la necesidad de construir un "sistema", el 27 de mayo de 2015 se publicó en el Diario Oficial de la Federación la reforma al título cuarto de la constitución política de los estados unidos mexicanos, para denominarlo: "de las responsabilidades de los servidores públicos, particulares vinculados con faltas administrativas graves o hechos de corrupción, y patrimonial del Estado".

Un año y dos meses después, en el Diario Oficial de la Federación de 18 de julio de 2016, se publicó el "Decreto por el que se expide la Ley General del Sistema Nacional Anticorrupción; la Ley General de Responsabilidades Administrativas, y la Ley Orgánica del Tribunal Federal de Justicia Administrativa". En la misma edición del Diario Oficial de la Federación, se emitieron el "Decreto por el que se reforman, adicionan y derogan diversas disposiciones del Código Penal Federal en Materia de Combate a la Corrupción", el "Decreto por el que se reforman y adicionan diversas disposiciones de la Ley Orgánica de la Procuraduría General de la República" y el "Decreto por el que se expide la Ley de Fiscalización y Rendición de Cuentas de la Federación; y se reforman el artículo 49 de la Ley de Coordinación Fiscal, y el artículo 70 de la Ley General de Contabilidad Gubernamental".

Sobre el Sistema Nacional Anticorrupción, el 5 de julio de 2017, se afirmaba que es la reforma federal más audaz que se haya promulgado para comenzar a contrarrestar las malas prácticas de la administración

2 En un breve recuento podemos destacar el contenido del Título IV "De la responsabilidad de los funcionarios públicos" de la Constitución de 1857 y la Ley sobre Delitos de los Altos Funcionarios de la Federación de 3 de noviembre de 1870, o "Ley Benito Juárez"; la Ley Reglamentaria de los artículos 104 y 105 de la Constitución federal, emitida el 6 de junio de 1886 por Porfirio Díaz. Posteriormente, ya durante la vigencia de la Constitución de 1917, se pública el 21 de febrero de 1940, la Ley de Responsabilidades de los Funcionarios y Empleados de la Federación, del Distrito y Territorios Federales y de los Altos Funcionarios de los Estados o "Ley Lázaro Cárdenas"; el 4 de enero de 1980 aparece la Ley de Responsabilidades de los Funcionarios y Empleados de la Federación, del Distrito Federal y de los Altos Funcionarios de los Estados, o "Ley López Portillo". El ciclo se cierra el 28 de diciembre de 1982, en el marco de la renovación moral de la sociedad, se reformó el título IV de la Constitución Política de los Estados Unidos Mexicanos para plasmar las responsabilidades civil, penal, administrativa y política, también se incorporó el principio non bis in idem.

Esta obra está bajo una Licencia Creative Commons

Atribución-NoComercial-SinDerivar 4.0 Internacional, IIJ-UNAM.

Boletín Mexicano de Derecho Comparado, núm. 152, pp. 787-803. 
pública mexicana y para bloquear a quienes, en general, abusan de las atribuciones o recursos públicos que la sociedad pone en sus manos. Además, se nos advertía que cuando entre en vigor pondrá en movimiento una compleja maquinaria institucional; modificará el anquilosado sistema de responsabilidades que habíamos venido arrastrando por décadas; exigirá que se conozcan datos que hasta hoy se habían venido ocultando o entregando por gotas; y promoverá nuevas vías para que la sociedad se organice y participe activamente en el combate a la corrupción. ${ }^{3}$

Sin embargo, al escribir estas líneas, en febrero de 2018, el sistema parece anquilosado. El Sistema Nacional Anticorrupción sufre la falta de consensos para la integración de sus órganos. Los actores institucionales no han sido capaces de nombrar al fiscal anticorrupción, tampoco se han expedido los nombramientos para los tres magistrados integrantes de la Tercera Sección de la Sala Superior, tampoco se han nombrado a los 15 magistrados integrantes de las cinco salas especializadas del Tribunal Federal de Justicia Administrativa. Además, está pendiente la emisión de toda la normatividad secundaria (relglamentos, lineamientos, politicas, manuales, etcétera) que haga eficiente y eficaz al sistema.

A los cuestionamientos formales le debemos agregar las quejas asociadas a su función sustantiva, en un país que día a día advierte como se multiplican los escándalos de corrupción. ${ }^{4}$

Así, tenemos dos visiones en torno al "Sistema Nacional Anticorrupción", la institucional que establece que es una reforma que eventualmente acabará con la corrupción, y la de algunos segmentos de la academia y la sociedad civil, donde existe un fuerte escepticismo en torno al sistema.

¿Cuál de las dos visiones es la más cercana a la realidad? ¿Cuál es el diseño formal de algunas de las normas que integran el Sistema Nacional Anticorrupción? ¿Contribuirán a enfrentar los dos temas más debatidos de la agenda nacional: corrupción e impunidad? Dedicaremos las siguientes líneas a intentar dar respuesta a estas interrogantes.

3 Merino, Mauricio, El Senado vs. el Sistema Anticorrupción”, El Universal, sección Opinión, disponible en: http://wrere.eluniversal.com.mx/entrada-de-opinion/articulo/mauricio-meri no/na cion/2017/07/5/el-senado-vs-el-sistema-anticorrupcion (fecha de consulta: 23 de febrero de 2018).

4 Como ejemplos podemos mencionar: la relación entre el actual presidente y Grupo Higa; la "casa en Malinalco"; el caso de Obrascón Huarte Lain (OHL) o el del tren México-Querétaro, el de Guillermo Padrés, César Duarte Jáquez, Javier Duarte de Ochoa, Sempra Energía, Oceanografía, Walmart, Odebrecht, Pemex, y otros más. 


\section{EL Sistema NAGiONAL ANTICORRUPGiÓN}

Para iniciar nuestros argumentos debemos destacar que en el paquete de reformas constitucionales de mayo de 2015 se incluyó la correspondiente al artículo 113 de la Constitución Política de los Estados Unidos Mexicanos, para plasmar las bases mínimas para la integración del Sistema Nacional Anticorrupción.

En ese precepto se destaca la creación del Sistema Nacional Anticorrupción, como una instancia de coordinación entre las autoridades de todos los órdenes de gobierno competentes en la prevención, detección y sanción de responsabilidades administrativas y hechos de corrupción, así como en la fiscalización y control de recursos públicos. De lo que se advierte la pretensión de abordar el problema de manera integral. Es importante destacar que todas estas instancias ya tenían competencia en la materia, la novedad es que se les obliga constitucionalmente a "coordinarse".

El Comité Coordinar del sistema se integra con los titulares de: 1) la Auditoría Superior de la Federación; 2) la Fiscalía Especializada en Combate a la Corrupción; 3) la secretaría del Ejecutivo Federal responsable del control interno; 4) el presidente del Tribunal Federal de Justicia Administrativa; 5) el presidente del organismo garante de la transparencia; 6) un representante del Consejo de la Judicatura Federal y 7) un miembro del Comité de Participación Ciudadana.

Además, se crea un Comité de Participación Ciudadana del Sistema integrado por cinco ciudadanos que se hayan destacado por su contribución a la transparencia, la rendición de cuentas o el combate a la corrupción y en su designación se establece la reserva de ley.

Como se podrá advertir, tenemos una instancia burocrática, similar a las comisiones intersecretariales ${ }^{5}$, en la que participan 12 personas, 6 de ellas servidores públicos pertenecientes a órganos que forman parte de los "poderes" Ejecutivo, Legislativo y Judicial y 5 miembros del comité de participación ciudadana, de los cuales, uno realiza una doble función, porque es el presidente del Comité Coordinador y a su vez miembro del Comité de Participación Ciudadana. En este sentido, los entes fiscalizados

5 Véase el artículo 21 de la Ley Orgánica de la Administración Pública Federal, en el que se destaca que el presidente de la República podrá constituir comisiones intersecretariales, para el despacho de asuntos en los que deban intervenir varias Secretarías de Estado o Departamentos Administrativos.

Esta obra está bajo una Licencia Creative Commons

Atribución-NoComercial-SinDerivar 4.0 Internacional, IIJ-UNAM.

Boletín Mexicano de Derecho Comparado, núm. 152, pp. 787-803. 
tienen mayoría en el Comité Coordinador del Sistema, porque de sus 7 integrantes, 6 son servidores públicos y sólo uno es "ciudadano".

Otro tema es que, desde el punto de vista estrictamente jurídico, el sistema está sobrecargado e incompleto, porque se compone: a) del Sistema Nacional Anticorrupción, b) el Sistema Nacional de Rendición de Cuentas, c) el Sistema Nacional de Fiscalización; d) el Sistema Nacional de Transparencia. Sin embargo, en la reforma constitucional se ignoró a: e) el sistema nacional de contabilidad gubernamental, $f$ ) el sistema nacional de presupuestación y deuda pública, y $g$ ) los sistemas de adquisiciones y obras gubernamentales. ${ }^{6}$ Así, una de las primeras problemáticas de no aceptar el carácter complejo del fenómeno corrupción, es que se "fortalecen" los cuatro primeros "sistemas" y se ignora a los tres últimos. Pero, además, esta sobrecarga de "sistemas" puede llevar a la inoperancia del combate a la corrupción mexicano.

Como se destaca en la fracción III del artículo 113 de la Constitución federal, las facultades de ese Comité Coordinador del Sistema, son:

\begin{tabular}{|l|l|}
\hline \multicolumn{1}{|c|}{ Facultad } & \multicolumn{1}{c|}{ Descripción } \\
\hline $\begin{array}{l}\text { a) Establecer mecanismos de coordina- } \\
\text { ción con los sistemas locales. }\end{array}$ & $\begin{array}{l}\text { Como la materia de "combate a la corrup- } \\
\text { ción es concurrente participan en ella la } \\
\text { Federación, las entidades federativas y los } \\
\text { municipios, lo anterior aunado a la inte- } \\
\text { racción con las instancias de esos órdenes } \\
\text { de gobierno encargados del combate a la } \\
\text { corrupción, lo que muestra lo complejo de } \\
\text { las necesidades de coordinación que tiene } \\
\text { el sistema. } \\
\text { Pero, además, pone el acento en el proble- } \\
\text { ma "federal", porque con estas leyes gene- } \\
\text { rales, las entidades federativas pierden ca- } \\
\text { pacidad de emitir libremente normas en su } \\
\text { espacio de competencia. }\end{array}$ \\
\hline $\begin{array}{l}\text { b) El diseño y promoción de políticas inte- } \\
\text { grales en materia de fiscalización y control } \\
\text { de recursos públicos, de prevención, con- } \\
\text { trol y disuasión de faltas administrativas y } \\
\text { hechos de corrupción, en especial sobre las } \\
\text { causas que los generan. }\end{array}$ & $\begin{array}{l}\text { Aquín se advierte la necesidad de generar } \\
\text { orientaciones dirigidas a quienes toman de- } \\
\text { cisiones en el contexto del combate a la co- } \\
\text { rupción, relacionados con la prevención } \\
\text { (causas), control y disuasión. }\end{array}$ \\
\hline
\end{tabular}

6 Evidentemente, en el Congreso de la Unión se ignoraron las implicaciones de la construcción de un "sistema" para el combate a la corrupción.

Esta obra está bajo una Licencia Creative Commons Atribución-NoComercial-SinDerivar 4.0 Internacional, IIJ-UNAM. Boletín Mexicano de Derecho Comparado, núm. 152, pp. 787-803. 


\begin{tabular}{|l|l|}
\hline \multicolumn{1}{|c|}{ Facultad } & \multicolumn{1}{|c|}{ Descripción } \\
\hline $\begin{array}{l}\text { c) La determinación de los mecanismos de } \\
\text { suministro, intercambio, sistematización } \\
\text { y actualización de la información que so- } \\
\text { bre estas materias generen las instituciones } \\
\text { competentes de los órdenes de gobierno. }\end{array}$ & $\begin{array}{l}\text { Generar plataformas de información sobre } \\
\text { la materia. }\end{array}$ \\
\hline $\begin{array}{l}\text { d) El establecimiento de bases y principios } \\
\text { para la efectiva coordinación de las autori- } \\
\text { dades de los órdenes de gobierno en mate- } \\
\text { ria de fiscalización y control de los recursos } \\
\text { públicos. }\end{array}$ & $\begin{array}{l}\text { Generar documentos rectores que orienten } \\
\text { la coordinación entre los diversos órdenes } \\
\text { combate a la corrupción. }\end{array}$ \\
\hline $\begin{array}{l}\text { e) La elaboración de un informe anual que del } \\
\text { contenga los avances y resultados del ejer- } \\
\text { cicio de sus funciones y de la aplicación de } \\
\text { políticas y programas en la materia. }\end{array}$ & Rendición de cuentas. \\
\hline
\end{tabular}

Así, ese Comité Coordinador funcionará como una especie de "organismo constitucional autónomo", porque podrá orientar la política, determinar mecanismos y establecer bases y principios sobre la materia de corrupción. El párrafo final del artículo 113 constitucional en análisis, impone a las entidades federativas la obligación de establecer sistemas locales anticorrupción similares al federal.

La norma reglamentaria del artículo 113 de la constitución federal, la Ley General del Sistema Nacional Anticorrupción, tiene 5 títulos, 10 capítulos, 60 artículos y 5 transitorios.

En su artículo 1o. destaca su carácter de "orden público” y su ámbito espacial de validez en todo el territorio nacional. En lo que se refiere a su objeto prescribe que es establecer las bases de coordinación entre la Federación, las entidades federativas, los municipios y las alcaldías de la Ciudad de México, para el funcionamiento del Sistema Nacional Anticorrupción, con la finalidad que las autoridades competentes prevengan, investiguen y sancionen las faltas administrativas y los hechos de corrupción.

El objeto se amplía en el artículo 6o., donde se establece que el Sistema Nacional tiene por objeto establecer principios, bases generales, políticas públicas y procedimientos para la coordinación entre las autoridades de todos los órdenes de gobierno en la prevención, detección y sanción de faltas administrativas y hechos de corrupción, así como en la fiscalización y control de recursos públicos. Además, se afirma que el sistema es una

Esta obra está bajo una Licencia Creative Commons

Atribución-NoComercial-SinDerivar 4.0 Internacional, IIJ-UNAM.

Boletín Mexicano de Derecho Comparado, núm. 152, pp. 787-803. 
instancia cuya finalidad es establecer, articular y evaluar la política en la materia. También se destaca que las "políticas públicas"7 que establezca el Comité Coordinador del Sistema Nacional deberán ser implementadas por todos los entes públicos y que la Secretaría Ejecutiva dará seguimiento a la implementación de dichas políticas.

Los objetivos, metas o propósitos de la ley, según su artículo 2o. son:

- Establecer mecanismos de coordinación entre los órganos de combate a la corrupción en la Federación, las entidades federativas, los municipios y las alcaldías de la Ciudad de México;

- Establecer las bases mínimas para la prevención de hechos de corrupción y faltas administrativas;

- Establecer las bases para la emisión de "políticas públicas" en el combate a la corrupción, así como en la fiscalización y control de los recursos públicos;

- Establecer las directrices básicas que definan la coordinación de las autoridades competentes para la generación de políticas públicas en materia de prevención, detección, control, sanción, disuasión y combate a la corrupción;

- Regular la organización y funcionamiento del Sistema Nacional, su Comité Coordinador y su Secretaría Ejecutiva, así como establecer las bases de coordinación entre sus integrantes;

- Establecer las bases, principios y procedimientos para la organización y funcionamiento del Comité de Participación Ciudadana;

7 La locución "políticas públicas” surge en 1951 y es obra de Harold D. Lasswell, supone que lo público es una dimensión de la actividad humana regulada e intervenida por la acción gubernamental. En su significado moderno de "policy" se vincula a la capacidad del gobierno para intervenir racionalmente en la solución de problemas públicos. Otra línea de reflexión se centra en el interés público, y retoma los problemas fundamentales del ser humano con amplitud y perspectiva global. (Véase Valenti Negrini, Giovanna, "Presentación", en Parsons, Wayne, Políticas públicas. Una introducción a la teoría y práctica del análisis de políticas públicas, trad. de Atenea Acevedo Aguilar, México, Flacso, 2013). En el mismo libro, pero atribuido a Wayne Parsons, se desataca que las políticas públicas se refieren a aquello que una vez Dewey expresara como "lo público y sus problemas", o sea, la forma en que llegan a la agenda política y a la agenda de las políticas públicas. Asimismo, estudian "cómo, por qué y para qué los gobiernos adoptan determinadas medidas y actúan o no actúan. Mi crítica está orientada al hecho de que en español la palabra "política" se refiere al campo de lo "público" y sus procesos y que la acción del gobierno la estudiamos en el "plan", "programa" y los diversos actos jurídicos. 
- Establecer las bases y políticas para la promoción, fomento y difusión de la cultura de integridad en el servicio público, así como de la rendición de cuentas, de la transparencia, de la fiscalización y del control de los recursos públicos;

- Establecer las acciones permanentes que aseguren la integridad y el comportamiento ético de los Servidores públicos, crear las bases mínimas para que todo órgano del Estado mexicano establezca políticas eficaces de ética pública y responsabilidad en el servicio público;

- Establecer las bases del Sistema Nacional de Fiscalización, y

- Establecer las bases mínimas para crear e implementar sistemas electrónicos para el suministro, intercambio, sistematización y actualización de la información que generen las instituciones competentes de los órdenes de gobierno.

Las facultades del Comité Coordinador se regulan en el artículo 9o. y se relacionan con "programas", "bases y principios", la "política nacional", "metodologías", "indicadores", "evaluaciones", "mecanismos", e "informes". Del contenido de esos objetivos se refrenda nuestro argumento de que ese Comité es en los hechos un "organismo constitucional autónomo", por las características de los objetivos y las facultades legales que se le otorgaron.

Del apartado de definiciones, contenido en el artículo 3o. podemos mencionar la creación del Sistema Nacional de Fiscalización, al que se define como el conjunto de mecanismos interinstitucionales de coordinación entre los órganos responsables de las tareas de auditoría gubernamental en los distintos órdenes de gobierno, con el objetivo de maximizar la cobertura y el impacto de la fiscalización en todo el país, con base en una visión estratégica, la aplicación de estándares profesionales similares, la creación de capacidades y el intercambio efectivo de información, sin incurrir en duplicidades u omisiones.

Otro artículo interesante de la Ley, es el 4o. que prescribe que los sujetos de esa norma son los entes públicos que integran el Sistema Nacional, porque esos "entes", definidos en el artículo 3o., son personas públicas, ${ }^{8}$

8 Véase la fracción VI del artículo 3o. de la Ley General del Sistema Nacional Anticorrupción, que destaca: "Entes públicos: los Poderes Legislativo y Judicial, los organismos constitucionales autónomos, las dependencias y entidades de la Administración Pública Federal y sus homólogos de las entidades federativas; los municipios y las alcaldías de la 
sin embargo, se deja fuera a los particulares relacionados con actos de corrupción. ${ }^{9}$ Lo que muestra otra de las carencias del "sistema".

También se debe destacar el contenido del artículo 5o. relacionado con los principios rectores que rigen el servicio público, porque aplicar principios éticos para un operador jurídico es un problema. Cuando se acepta, por ejemplo, que en un sistema jurídico coexisten normas y principios, se tienen que construir sistemas de interpretación apropiados para cada uno, a través de la "subsunción" y la "ponderación".

Lo anterior se complica, porque en el artículo 109, fracción III, de la Constitución Política de los Estados Unidos Mexicanos se establece como marco ético para el servicio público la legalidad, honradez, lealtad, imparcialidad y eficiencia. En cambio, en el artículo 5o. de la Ley comentada encontramos como "principios rectores que rigen el servicio": legalidad, objetividad, profesionalismo, honradez, lealtad, imparcialidad, eficiencia, eficacia, equidad, transparencia, economía, integridad y competencia por mérito. Sin embargo, el tema se complica porque el artículo 7o. de la Ley General de Responsabilidades Administrativas destaca que los Servidores Públicos observarán en el desempeño de su empleo, cargo o comisión, los principios de disciplina, legalidad, objetividad, profesionalismo, honradez, lealtad, imparcialidad, integridad, rendición de cuentas, eficacia y eficiencia que rigen el servicio público.

En este sentido, si combinamos el contenido de los artículos mencionados, tenemos que a un servidor público se le pueden aplicar once "principios", a saber: 1) legalidad, 2) disciplina, 3) honradez, 4) objetividad, 5) profesionalismo, 6) imparcialidad, 7) lealtad, 8) eficiencia, 9) eficacia, 10) equidad, 11) integridad, 12) rendición de cuentas, 13) transparencia, 14) economía, y 15) competencia por mérito. Por lo que surge una serie de cuestiones: ¿es constitucional que las leyes secundarias vayan más allá de lo que prescribe la constitución federal? ¿Es conveniente imponer principios no derivados de la constitución federal a los

Ciudad de México y sus dependencias y entidades; la Procuraduría General de la República y las fiscalías o procuradurías locales; los órganos jurisdiccionales que no formen parte de los poderes judiciales; las empresas productivas del Estado, así como cualquier otro ente sobre el que tenga control cualquiera de los poderes y órganos públicos antes citados delos tres órdenes de gobierno".

9 Que sí se consideran en la reforma constitucional y en la Ley General de Responsabilidades Administrativas. 
servidores públicos? ¿Este exceso del legislador ordinario no vicia de inconstitucionalidad al sistema al exceder la "tipicidad" constitucional? ${ }^{10}$

Continuando, el artículo 5o. de la Ley General del Sistema Nacional Anticorrupción también impone a los entes públicos obligados de crear y mantener condiciones estructurales y normativas que permitan el adecuado funcionamiento del Estado en su conjunto, y la actuación ética y responsable de cada servidor público. Esta norma, en lo que se refiere al "adecuado funcionamiento del Estado en su conjunto", invade competencias de otros entes públicos.

Como ejemplo, podemos mencionar que en términos del artículo 80 de la Constitución Política de los Estados Unidos Mexicanos, se deposita el ejercicio del Supremo Poder Ejecutivo de la Unión en un sólo individuo, que se denominará "presidente de los Estados Unidos Mexicanos", lo que significa que este servidor público es jefe de Estado y jefe de gobierno o de la administración pública. Lo anterior se replica para los ejecutivos locales en las constituciones de las entidades federativas. Así, los autores de las leyes del sistema anticorrupción ignoran nuestro régimen legal, lo que también cuestiona al "sistema".

En lo que se refiere a la estructura funcional del Sistema Nacional Anticorrupción, según el artículo 7o., se compone por: a) los integrantes del Comité Coordinador; $b$ ) el Comité de Participación Ciudadana; $c$ ) el Comité Rector del Sistema Nacional de Fiscalización, y d) los Sistemas Locales, quienes concurrirán a través de sus representantes.

Otro tema importante se regula en el artículo 24 de la Ley General del Sistema Nacional Anticorrupción, que crea a la Secretaría Ejecutiva del Sistema Nacional, como un organismo descentralizado, no sectorizado, con personalidad jurídica y patrimonio propio, con autonomía técnica y de gestión, con sede en la Ciudad de México, instancia a la que se dota de una estructura operativa para la realización de sus atribuciones, objetivos y fines.

10 Aquí es importante destacar que "contradicción" significa "acción y efecto de contradecir". Contradecir, en uno de sus significados, es "negar lo que se da por cierto". Si aceptamos que la Constitución "da por cierto" los principios aplicables al servicio público, debemos preguntarnos: ¿pueden las normas inferiores ir más allá de la Constitución, agravando el régimen de responsabilidad del servidor público, o debería ser numerus clausus? Véase Tesis P./J. 25/2000, Semanario Fudicial de la Federación y su Gaceta, Novena Época, t. XI, marzo de 2000, p. 38, de rubro "LEYES. INCONSTITUCIONALIDAD DE LAS", en la que se destaca lo siguiente: "La inconstitucionalidad de una ley surge de su contradicción con un precepto de la Constitución y no de oposición entre leyes secundarias".

Esta obra está bajo una Licencia Creative Commons

Atribución-NoComercial-SinDerivar 4.0 Internacional, IIJ-UNAM.

Boletín Mexicano de Derecho Comparado, núm. 152, pp. 787-803. 
Para cerrar estas breves líneas en torno al sistema nacional anticorrupción, es importante mencionar que ningún esfuerzo de combate a la corrupción tendrá éxito si no se involucra a toda la sociedad, lo que implica utilizar en las normas un lenguaje susceptible de compresión por todos los involucrados, lo que nos lleva a considerar la necesidad de evaluar cuidadosamente la idoneidad de incorporar aspectos técnicos a la legislación.

También, que es necesario esperar a que esta herramienta de combate a la corrupción ejerzas sus funciones de manera integral; sin embargo, se puede aventurar que la eficacia y eficiencia del Sistema Nacional Anticorrupción será tema de análisis y debate futuro en el foro jurídico nacional.

\section{LA LEY GENERAL DE RESPONSABILIDADES ADMINISTRATIVAS}

La complejidad actual del sistema del combate a la corrupción en México se advierte con la existencia de otra norma importante, que surge con la reforma legal de julio de 2016, es la Ley General de Responsabilidades Administrativas que consta de 2 Libros, 6 Títulos, 23 Capítulos, 22 Secciones, 229 Artículos y 5 Transitorios.

Esta norma tiene su base constitucional en el artículo 109 de la Constitución Política de los Estados Unidos Mexicanos, que regula lo relacionado con la responsabilidad administrativa, entre ellos los supuestos para la aplicación de sanciones administrativas: cuando los servidores públicos incurran en actos u omisiones que afecten la legalidad, honradez, lealtad, imparcialidad y eficiencia que deban observar en el desempeño de sus empleos, cargos o comisiones.

Además, en esa norma constitucional - el artículo 109, fracción III-, también se contiene el catálogo de sanciones aplicables a los servidores públicos que infrinjan las obligaciones a su cargo, o sea, amonestación, suspensión, destitución e inhabilitación, así como sanciones económicas, de acuerdo con los beneficios obtenidos o con los daños y perjuicios causados el responsable por sus actos u omisiones. Además, establece el principio de reserva de ley para los procedimientos, la investigación y sanción de esos actos u omisiones.

También, perfila el nuevo procedimiento administrativo, al destacar la existencia de autoridades investigadoras, sustanciadoras y resolutoras. Prescribe que las faltas administrativas graves las investigan y substancian la Auditoría Superior de la Federación y los órganos internos de control, 
o sus homólogos en las entidades federativas, y las resuelva el Tribunal de Justicia Administrativa competente.

Como se establece en la fracción IV del mismo precepto constitucional, los tribunales de justicia administrativa pueden imponer las sanciones económicas, inhabilitación para participar en adquisiciones, arrendamientos, servicios u obras públicas, así como el resarcimiento de los daños y perjuicios ocasionados, a los particulares que incurran en faltas administrativas graves. En el apartado mencionado, también prescribe que las personas morales pueden ser sancionadas cuando los actos vinculados con faltas administrativas graves sean realizadas por las personas físicas que actúen a nombre o representación y en beneficio de ella, en este caso, se les pueden imponer sanciones como la suspensión de actividades y la disolución o intervención de la sociedad respectiva; también se menciona que la sanción se ejecutará hasta que la resolución sea definitiva. Por último, se establece la reserva de ley en estas materias.

Por último, el precepto constitucional mencionado, prescribe que las demás faltas (las "faltas administrativas" o las "faltas administrativas no graves”, en sentido estricto) y sanciones administrativas, serán conocidas y resueltas por los órganos internos de control, con lo que se mantiene el viejo problema de legalidad que instituye a los órganos internos de control en juez y parte.

Además, la Ley General de Responsabilidades Administrativa, y regula temas como: 1) su objeto y objetivos; 2) establece los conceptos o el apartado hermenéutica de la ley; 3) los sujetos de la ley o ámbito de validez personal; 4) las autoridades facultadas para aplicar la ley; 5) los órganos competentes para la investigación, substanciación y calificación de las faltas administrativas; 6) los órganos competentes para resolver la imposición de sanciones; 7) los mecanismos generales de prevención e instrumentos de rendición de cuentas; 8) la integridad de las personas morales; 9) los instrumentos de rendición de cuentas, como las declaraciones y de los sujetos obligados a presentar declaración (patrimonial y de intereses); 10) procedimiento en el caso de discrepancias entre la declaración y el incremento del patrimonio; 11) régimen de los servidores públicos que participan en contrataciones públicas; 12) faltas administrativas de los servidores públicos y actos de particulares vinculados con faltas administrativas graves.

Para esta exposición cabe destacar que los actos u omisiones que vinculan a los servidores a responsabilidad por faltas administrativas, son:

Esta obra está bajo una Licencia Creative Commons

Atribución-NoComercial-SinDerivar 4.0 Internacional, IIJ-UNAM.

Boletín Mexicano de Derecho Comparado, núm. 152, pp. 787-803. 


\begin{tabular}{|c|c|c|c|}
\hline $\begin{array}{l}\text { Principios y directrices } \\
\text { Artículo } 7 \mathrm{o} .\end{array}$ & $\begin{array}{l}\text { Faltas administrativas graves } \\
\text { Artículos del } 49 \text { y } 50\end{array}$ & $\begin{array}{l}\text { Faltas administrativas graves } \\
\text { Artículos del } 51 \text { al } 64\end{array}$ & $\begin{array}{c}\text { Actos de particulares vinculados } \\
\text { con faltas administrativas graves } \\
\text { Artículos } 65 \text { al } 72\end{array}$ \\
\hline $\begin{array}{l}\text { Principios: } \\
\text { 1. Disciplina } \\
\text { 2. Legalidad } \\
\text { 3. Objetividad } \\
\text { 4. Profesionalismo } \\
\text { 5. Honradez } \\
\text { 6. Lealtad } \\
\text { 7. Imparcialidad } \\
\text { 8. Integridad } \\
\text { 9. Rendición de cuentas } \\
\text { 10. Eficacia y } \\
\text { 11. Eficiencia } \\
\text { Directrices: } \\
\text { 1. Actuar conforme a las leyes, } \\
\text { reglamentos y demás dispo- } \\
\text { siciones jurídicas. } \\
\text { 2. Conducirse con rectitud. } \\
\text { 3. Abstenerse de buscar o acep- } \\
\text { tar compensaciones, presta- } \\
\text { ciones, dádivas, obsequios o } \\
\text { regalos. } \\
\text { 4. Satisfacer el interés superior } \\
\text { de las necesidades colectivas. } \\
\text { 5. Dar a las personas en gene- } \\
\text { ral el mismo trato. } \\
\text { 6. Actuar conforme a una cul- } \\
\text { tura de servicio orientada al } \\
\text { logro de resultados. }\end{array}$ & $\begin{array}{l}\text { 1. Cumplir con las funciones, } \\
\text { atribuciones y comisiones en- } \\
\text { comendadas. } \\
\text { 2. Observar en su desempeño dis- } \\
\text { ciplina y respeto. } \\
\text { 3. Denunciar los actos u omisio- } \\
\text { nes que puedan constituir fal- } \\
\text { tas administrativas. } \\
\text { 4. Atender las instrucciones de } \\
\text { sus superiores relacionadas con } \\
\text { el servicio público. } \\
\text { 5enunciar la instrucción o en- } \\
\text { comienda contraria a las dis- } \\
\text { posiciones relacionadas con el } \\
\text { servicio público. } \\
\text { Presentar en tiempo y forma las } \\
\text { declaraciones de situación pa- } \\
\text { trimonial y de intereses. } \\
\text { Registrar, integrar, custodiar y } \\
\text { cuidar la documentación e in- } \\
\text { formación que tenga bajo su } \\
\text { responsabilidad, e impedir o evi- } \\
\text { tar su uso, divulgación, sustrac- } \\
\text { ción, destrucción, ocultamiento } \\
\text { o inutilización indebidos. } \\
\text { 8. Supervisar que los servidores } \\
\text { públicos sujetos a su dirección, } \\
\text { cumplan con las disposiciones. }\end{array}$ & $\begin{array}{l}\text { 1. Cohecho. } \\
\text { 2. Peculado. } \\
\text { 3. Desvío de recursos públicos. } \\
\text { 4. Utilización indebida de infor- } \\
\text { mación. } \\
\text { 5. Abuso de funciones. } \\
\text { 6. Actuación bajo Conflicto de } \\
\text { Interés. } \\
\text { 7. Contratación indebida. } \\
\text { 8. Enriquecimiento oculto u ocul- } \\
\text { tamiento de Conflicto de In- } \\
\text { terés. } \\
\text { 9. Tráfico de influencias. } \\
\text { 10. Utilizar la posición que su em- } \\
\text { pleo, cargo o comisión para } \\
\text { inducir a que otro servidor pú- } \\
\text { blico efectúe, retrase u omita } \\
\text { realizar algún acto de su com- } \\
\text { petencia. } \\
\text { 11. Encubrimiento. } \\
\text { 12. Desacato. } \\
\text { 13. Obstrucción de la justicia. }\end{array}$ & $\begin{array}{l}\text { 1. Soborno. } \\
\text { 2. Participación ilícita en } \\
\text { procedimientos adminis- } \\
\text { trativos. } \\
\text { 3. Tráfico de influencias pa- } \\
\text { ra inducir a la autoridad. } \\
\text { 4. Responsable de utiliza- } \\
\text { ción de información falsa. } \\
\text { 5. Colusión. } \\
\text { 6. Uso indebido de recursos } \\
\text { públicos } \\
\text { 7. contratación indebida de } \\
\text { exservidores públicos }\end{array}$ \\
\hline
\end{tabular}


Esta revista forma parte del acervo de la Biblioteca Jurídica Virtual del Instituto de Investigaciones Jurídicas de la UNAM

\begin{tabular}{|c|c|c|c|}
\hline $\begin{array}{c}\text { Principios y directrices } \\
\text { Artículo } 7 \mathrm{o} .\end{array}$ & $\begin{array}{l}\text { Faltas administrativas graves } \\
\text { Artículos del } 49 \text { y } 50\end{array}$ & $\begin{array}{l}\text { Faltas administrativas graves } \\
\text { Artículos del } 51 \text { al } 64\end{array}$ & $\begin{array}{c}\text { Actos de particulares vinculados } \\
\text { con faltas administrativas graves } \\
\text { Artículos } 65 \text { al } 72\end{array}$ \\
\hline $\begin{array}{l}\text { 7. Actuar conforme a una cul- } \\
\text { tura de servicio orientada al } \\
\text { logro de resultados. } \\
\text { 8. Administración honesta de } \\
\text { recursos públicos. } \\
\text { 9. Promover, respetar, proteger } \\
\text { y garantizar los derechos hu- } \\
\text { manos. } \\
\text { 10. Corresponder a la confianza } \\
\text { social. } \\
\text { 11. Tener una vocación absoluta } \\
\text { de servicio a la sociedad. } \\
\text { 12. Evitar y dar cuenta de los in- } \\
\text { tereses que puedan entrar en } \\
\text { conflicto. } \\
\text { 13. Abstenerse de realizar tra- } \\
\text { tos o promesas privadas } \\
\text { que comprometan al Estado } \\
\text { mexicano. }\end{array}$ & $\begin{array}{l}\text { 9. Rendir cuentas sobre el ejerci- } \\
\text { cio de las funciones. } \\
\text { 10. Colaborar en los procedimien- } \\
\text { tos judiciales y administrativos. } \\
\text { 11. Cuidar los temas de conflicto } \\
\text { de intereses. } \\
\text { 12. Se considera falta administra- } \\
\text { tiva no grave, los daños y per- } \\
\text { juicios que, de manera culposa } \\
\text { o negligente cause un servidor } \\
\text { público a la Hacienda Pública } \\
\text { o al patrimonio de un Ente pú- } \\
\text { blico. }\end{array}$ & & \\
\hline
\end{tabular}


Como se advierte, un servidor público deberá cumplir con 11 principios, 12 directrices, abstenerse de incurrir en 12 causales de falta no grave y abstenerse de incurrir en 13 causales de falta grave. Lo que hace un total de 48 obligaciones que se imponen a cada servidor público, lo anterior pone en evidencia lo complejo que es el actual régimen de responsabilidades administrativas.

También, en la norma en análisis se regulan: 13) las faltas de particulares en situación especial, 14) la prescripción de la responsabilidad administrativa, 15) las sanciones por faltas administrativas no graves, 16) las sanciones para los servidores públicos por faltas graves, 17) las sanciones por faltas de particulares. También tiene un apartado de 18) disposiciones comunes para la imposición de sanciones por faltas administrativas graves y faltas de particulares.

En su aspecto procesal, la Ley General de Responsabilidades Administrativas, norma: 19) el inicio de la investigación y la investigación; 20) la calificación de las faltas administrativas, el informe de presunta responsabilidad y su contenido; 21) la calificación de faltas no graves; 22) el recurso de inconformidad; 23) el procedimiento de responsabilidad administrativa; 24) los principios procesales, 25) la interrupción de la prescripción, 26) las partes y las autorizaciones procesales; 27) el inicio del procedimiento de responsabilidad administrativa; 28) las partes en el procedimiento de responsabilidad administrativa; 29) la supletoriedad; 30) los medios de apremio; 31) las medidas cautelares; 32) los incidentes; 33) las notificaciones; 34) la improcedencia y el sobreseimiento; 35) las pruebas; 36) la audiencia; 37) las reglas en materia de actuaciones y resoluciones; 38) el procedimiento de responsabilidad administrativa ante las Secretarías y Órganos internos de control; 39) las resoluciones; 40) los medios de impugnación; 41) la ejecución de sentencias; 42) cumplimiento y ejecución de sanciones por faltas administrativas no graves; 43) cumplimiento y ejecución de sanciones por faltas administrativas graves y faltas de particulares.

Como se advierte, los 220 artículos de la Ley General de Responsabilidades Administrativas nos remiten temáticamente a 43 grandes divisiones de aspectos sustantivos y procesales.

También, debemos mencionar que existen otras normas involucradas en el combate a la corrupción, como son la Ley Orgánica del Tribunal Federal de Justicia Administrativa, al Código Penal Federal en Materia de 
Combate a la Corrupción, la Ley Orgánica de la Procuraduría General de la República, la Ley de Fiscalización y Rendición de Cuentas de la Federación y la reforma a los artículos 49, de la Ley de Coordinación Fiscal, y 70 de la Ley General de Contabilidad Gubernamental.

Además, es importante destacar que la efectiva reforma anticorrupción es la reforma penal, contenida en el "Decreto" por el que "se reforman, adicionan y derogan diversas disposiciones del Código Penal Federal en materia de combate a la corrupción". Lo que muestra que en materia de combate regresamos al siglo XIX, a leyes como "la Juárez", la "Porfirio Díaz", "Lázaro Cárdenas" o "López Portillo", sin embargo, con una limitante, en esas leyes se tenía en claro el carácter penal de las infracciones, faltas y delitos en los que incurriera un servidor público. En la Ley General de Responsabilidades Administrativas se mantiene el esquema de una "responsabilidad administrativa", por lo que, los vicios de ese esquema del sistema anterior, se trasladan al nuevo sistema.

Para cerrar el análisis podemos dar respuesta a las preguntas planteadas, afirmando que es temprano para destacar el destino de la reforma anticorrupción mexicana, sin embargo, atendiendo a los problemas y carencias destacados, no existe espacio para la visión optimista, el diseño formal de las normas que integran el Sistema Nacional Anticorrupción muestra una complejidad sustantiva y procesal que difícilmente contribuye a enfrentar los dos temas más debatidos de la agenda nacional: corrupción e impunidad.

Un último tema es la posibilidad del uso político de los mecanismos de rendición de cuentas, del derecho penal, del control interno y externo; la justicia administrativa, la transparencia, y a la judicatura federal, legitimado lo anterior con una "supuesta" participación ciudadana.

\section{BibliografíA}

MÁRQuez Gómez, Daniel (coord.), Corrupción y Sistema Nacional Anticorrupción: temas y problemas, México, Tribunal de lo Contencioso Administrativo del Estado de Guanajuato-Novum, 2016.

MÁRQUez Gómez, Daniel, El marco jurídico para la operación del Sistema $\mathrm{Na}$ cional Anticorrupción. Constitucionalidad y legalidad del combate a la corrupción mexicano, México, Tribunal de Justicia Administrativa del Estado de Guanajuato-Novum, 2017.

Esta obra está bajo una Licencia Creative Commons

Atribución-NoComercial-SinDerivar 4.0 Internacional, IIJ-UNAM.

Boletín Mexicano de Derecho Comparado, núm. 152, pp. 787-803. 
MÁrQUez Gómez, Daniel, El marco jurídico para la operación del Sistema Nacional Anticorrupción. Combate a la corrupción, fiscalización y transparencia, México, Tribunal de Justicia Administrativa del Estado de Guanajuato-Novum, 2017.

MÁRQUEz, Daniel, "La diasdoralogía como el estudio integral del fenómeno de la corrupción", ponencia en el IX Congreso Mexicano y II Iberoamericano de Derecho Administrativo.

Merino, Mauricio, "El Senado vs. el Sistema Anticorrupción”, El Universal, sección Opinión, disponible en: http://wrew.eluniversal.com.mx/entradade-opinion/articulo/mauricio-merino/nacion/2017/07/5/el-senado-vs-el-sistema-anticorrupcion (fecha de consulta: 23 de febrero de 2018).

VAlenti Negrini, Giovanna, "Presentación", en Parsons, Wayne, Políticas públicas. Una introducción a la teoría y práctica del análisis de politicas públicas, trad. de Atenea Acevedo Aguilar, México, Flacso, 2013. 